\title{
Postchemotherapy and Tumor-Selective Targeting with the La-Specific DAB4 Monoclonal Antibody Relates to Apoptotic Cell Clearance
}

\author{
Fares Al-Ejeh*1, Alexander H. Staudacher*2, Douglas R. Smyth ${ }^{3}$, Jocelyn M. Darby², Delphine Denoyer ${ }^{4}$, \\ Chris Tsopelas $^{3}$, Rodney J. Hicks ${ }^{4,5}$, and Michael P. Brown ${ }^{2,6}$ \\ ${ }^{1}$ Signal Transduction Laboratory, QIMR Berghofer Medical Research Institute, Brisbane, Australia; ${ }^{2}$ Translational Oncology \\ Laboratory, Centre for Cancer Biology, SA Pathology, Adelaide, Australia; ${ }^{3}$ Department of Nuclear Medicine, PET and Bone \\ Densitometry, Royal Adelaide Hospital, Adelaide, Australia; ${ }^{4}$ Division of Cancer Research, Peter MacCallum Cancer Centre, \\ Melbourne, Australia; ${ }^{5}$ Centre for Cancer Imaging, Peter MacCallum Cancer Centre, Melbourne, Australia; and ${ }^{6}$ Cancer Clinical \\ Trials Unit, Royal Adelaide Hospital, and School of Medicine, University of Adelaide, Adelaide, Australia
}

Early identification of tumor responses to treatment is crucial for
devising more effective and safer cancer treatments. No widely ap-
plicable, noninvasive method currently exists for specifically detect-
ing tumor cell death after cytotoxic treatment and thus for predicting
treatment outcomes. Methods: We have further characterized the
targeting of the murine monoclonal antibody DAB4 specifically to
dead tumor cells in vitro, in vivo, and in clinical samples. We found
that sustained DAB4 binding to treated cells was closely associated
with markers of intrinsic apoptosis and DNA double-strand break
formation. In a competition binding assay, DAB4 bound EL4 murine
thymic lymphoma cells in preference to the normal counterpart of
murine thymocytes. Defective in vivo clearance of apoptotic cells
augmented in vivo accumulation of DAB4 in tumors particularly after
chemotherapy but was unchanged in normal tissues. Tumor target-
ing of DAB4 was selective for syngeneic murine tumors and for human
tumor xenografts of prostate cancer (PC-3) and pancreatic cancer
(Panc-1) before and more so after chemotherapy. Furthermore, DAB4
was shown to bind to dead primary acute lymphoblastic leukemic
blasts cultured with cytotoxic drugs and dead epithelial cancer cells
isolated from peripheral blood of small cell lung carcinoma patients
given chemotherapy. Conclusion: Collectively, these results further
demonstrate the selectivity of DAB4 for chemotherapy-induced dead
tumor cells. This postchemotherapy selectivity is related to a relative
increase in the availability of DAB4-binding targets in tumor tissue
rather than in normal tissues. The in vitro findings were translated in
vivo to human xenograft models and to ex vivo analyses of clinical
samples, providing further evidence of the potential of DAB4 as a
marker of tumor cell death after DNA-damaging cytotoxic treatment
that could be harnessed as a predictive marker of treatment responses.

Key Words: APOMAB; apoptosis; La; DAB4; chemotherapy; therapy response

J Nucl Med 2014; 55:772-779

DOI: 10.2967/jnumed.113.130559

Received Aug. 13, 2013; revision accepted Dec. 2, 2013.

For correspondence or reprints contact: Michael P. Brown, Cancer Clinical Trials Unit, MDP11, Level 4, East Wing, Royal Adelaide Hospital, SA 5000, Adelaide, Australia.

E-mail: michael.brown@health.sa.gov.au

${ }^{*}$ Contributed equally to this work.

Published online Mar. 27, 2014.

COPYRIGHT (c) 2014 by the Society of Nuclear Medicine and Molecular Imaging, Inc.
C ancer is a major cause of mortality and morbidity worldwide, and the care and treatment of cancer patients places an intense demand on health systems. Cytotoxic chemotherapy or radiotherapy may not be completely effective even in most patients, and the personal and socioeconomic burdens mount when ineffective treatments are attended by toxicities. It is therefore important to determine whether a patient is responding as soon as possible after initiating treatment. Treatment responses are conventionally assessed by the structural imaging modalities of CT, MR imaging, and ultrasound (1). Additional functional information can be provided by hybrid imaging using CT and ${ }^{18}$ F-FDG PET (2). However, tumor uptake of ${ }^{18}$ F-FDG can be variable $(3,4)$, limiting sensitivity, and uptake by inflamed tissue (5) limits specificity. Hence, there is an unmet clinical need for noninvasive, real-time diagnostic imaging techniques to achieve early and accurate identification of tumor biologic responses to cancer treatments.

One of the most important and desirable properties of an effective anticancer treatment is the induction of tumor cell death. Invasive tumor sampling methods indicate that measures of tumor cell death such as an apoptotic index, which derives from counts of TdTmediated biotin-dUTP nick-end labeling (TUNEL)-positive cells, may predict treatment outcomes $(6,7)$. Noninvasive imaging methods have used radiolabeled Annexin V, a tracer that targets phosphatidylserine expressed on the plasma membrane of cells undergoing apoptosis (8), in early-phase clinical studies of tumor cell death in response to chemotherapy. Although radiolabeled Annexin V may represent a promising cell-death detection technology for therapy response monitoring $(9,10)$, outstanding problems with tumor-tobackground ratio and optimal imaging times remain for product design and clinical development. Moreover, phosphatidylserine is broadly expressed in inflamed tissue, in atherosclerotic plaques, during thrombosis (11-14), and in dead noncancerous cells, which all reduce the tumor specificity of Annexin V.

We have discovered that malignant cell lines overexpress the La antigen, which is an RNA-binding chaperone primarily localized to the nucleus although it may shuttle to cytoplasm (15). Moreover, we found that La can be targeted specifically in dead tumor cells by the monoclonal antibody (mAb) DAB4 (APOMAB; Medvet Science Pty Ltd.) (16-18). La is recruited to DNA double-strand breaks (DSBs) caused by cytotoxic treatment and is cross-linked in 
necrotic malignant cells by transglutaminase-2, thus stabilizing the antigen and making it accessible for DAB4 binding (16). Consequently, DAB4 has greater avidity for dead tumor cells than analogous dead primary cells in vitro (16). DAB4 also binds with high specificity to dead tumors cells in vivo, which we have exploited by radiolabeling DAB4 with ${ }^{111}$ In for tumor imaging (18) and with ${ }^{90} \mathrm{Y}(17)$ and ${ }^{177} \mathrm{Lu}$ (19) for tumor therapy. These data indicate that DAB4 has the highest avidity for dead, necrotic tumor cells that have died as a result of DNA-damaging treatment with cytotoxic drugs or ionizing radiation $(16,17,20)$. Therefore, it seems feasible that DAB4 or its derivatives may have clinical utility as in vivo diagnostic imaging agents for the specific detection of tumor cell death after cytotoxic treatments including radionuclide therapies capable of inducing DNA DSBs.

In the present study using in vitro and in vivo models, we have further characterized the selectivity of DAB4 for dead tumor cells and the factors that may influence this selectivity. In particular, DAB4 binding to dead tumor cells in human xenograft models was examined as well as the selectivity of DAB4 for dead tumor cells sampled from the blood of cancer patients after chemotherapy. Because of this selectivity, this study provides further evidence to support the diagnostic use of DAB4 in human malignancy.

\section{MATERIALS AND METHODS}

\section{Ethics Statement}

The Human Research Ethics Committee of the Royal Adelaide Hospital approved the use of blood from consenting healthy volunteers and patients with acute lymphoblastic leukemia (ALL) or small cell lung carcinoma (SCLC). All subjects signed a written informed consent form. Experiments involving the use of mice were approved by the Animal Ethics Committee of the Institute of Medical and Veterinary Sciences, Adelaide. In the use and care of the mice, we followed the humane research principles of replacement, reduction, and refinement endorsed by the National Health and Medical Research Council of Australia. Animal imaging at the Peter MacCallum Cancer Centre was approved by its Animal Ethics Committee.

\section{Cell Culture, mAb Production, and Conjugation}

The cell lines were obtained from American Type Cell Culture. The human acute T-cell leukemia Jurkat cell line and the murine thymic lymphoma EL4 cell line were maintained in RPMI-1640 medium containing 5\% fetal calf serum (FCS; JRH Biosciences Inc.). PC-3 cells and Panc- 1 cells were maintained in RPMI-1640 containing 10\% FCS.

DAB4 is a subclone of the murine anti-La/SS-B 3B9 hybridoma originated by Dr. Michael Bachmann (21), which was selected on the basis of higher binding to a defined epitope of the La antigen. 3B9 was provided as a gift from Professor Tom Gordon (Flinders Medical Centre) (22). The DAB4 mAb and isotype control Sal5 $\mathrm{mAb}$ were prepared, purified, and conjugated to the metal chelator DOTA $N$-hydroxysuccinimidyl ester (NHS) (Macrocyclics) as previously described $(16,18)$.

\section{Fluorocytometric Detection of DAB4 Binding in Jurkat Cells and Competition Assay for DAB4 Binding}

Jurkat cells $\left(10^{6}\right.$ cells $\left./ \mathrm{mL}\right)$ were untreated or treated with cisplatin (20 $\mu \mathrm{g} / \mathrm{mL}$ ) (Bristol-Myers Squibb Co.), 15 Gy of ionizing radiation (5 Gy/min), or anti-CD95/Fas IgM antibody $(250 \mathrm{ng} / \mathrm{mL}$ ) (clone $\mathrm{CH} 11$; Millipore). Cells were collected, fixed, permeabilized, and stained for phospho-histone H2AX (clone JBW301; Millipore) and activated caspase-3 (Millipore) as previously described (16). Twenty thousand cells were acquired using a FACScan flow cytometer (BD Biosciences) and analyzed using WinMDI (version 2.8; Scripps Research Institute).

Thymus glands were harvested from C57BL/6 mice and thymocytes isolated by gently grinding the tissue with glass slides into RPMI-1640 medium containing $10 \%$ FCS and passing through a 40- $\mu \mathrm{m}$ mesh sieve. After thymocytes were incubated in red blood cell lysis buffer (ammonium chloride [8.3 g/L] in 0.01 M Tris-HCl buffer, $\mathrm{pH} 7.4$ ) for $10 \mathrm{~min}$, the thymocytes and EL4 cells were cultured in RPMI-1640 medium with $10 \%$ FCS and cisplatin $(20 \mu \mathrm{g} / \mathrm{mL})$ for $48 \mathrm{~h}$. Dead thymocytes were labeled with $1 \mu \mathrm{M}$ CellTrace carboxyfluorescein succinimidyl ester (Cell Proliferation Kit; Life Technologies) following the manufacturer's instructions, washed, and incubated with DAB4 alone $(10 \mu \mathrm{g} / \mathrm{mL})$ or in the presence of an increasing number of dead EL4 cells. After 30 min, cells were washed and incubated with goat antimouse IgG PE-Alexa Fluor680 $(2 \mu \mathrm{g} / \mathrm{mL}$ ) (Life Technologies) for $30 \mathrm{~min}$ at room temperature. After washing, 20,000 cells were analyzed by flow cytometry.

\section{Animal Studies Using C1q Knock-Out $\left(\mathrm{C}_{1 q^{-}}{ }^{-/-}\right)$Mice}

Six- to 8-wk-old female C57BL/6 mice and $\mathrm{Clqa}^{-/-}$mice (23) were either untreated (control; $n=5$ ) or received intraperitoneal injections of $10^{8}$ dead Jurkat cells, which had been treated with cisplatin $(20 \mu \mathrm{g} / \mathrm{mL})$ for $96 \mathrm{~h}(n=5)$. Mice were humanely killed $24 \mathrm{~h}$ later, and whole blood was collected via cardiac puncture. Plasma was isolated using a ficoll gradient, and double-stranded DNA (dsDNA) present in the plasma was assayed using the Quant-iT PicoGreen kit (Life Technologies) per the manufacturer's instructions.

As previously described, EL4 tumors were established in the right flank of 6- to 8-wk-old female C57BL/6 or $\mathrm{Cl}_{\mathrm{qa}} \mathrm{a}^{-1-}$ mice, which had been backcrossed for at least 10 generations onto a C57BL/6 background (18). When tumors reached $120-130 \mathrm{~mm}^{3}$, mice were either untreated (control; $n=5$ ) or treated with intraperitoneal injections of etoposide (19 mg/kg; Pfizer Inc.) and cyclophosphamide $(25 \mathrm{mg} / \mathrm{kg}$; Bristol-Myers Squibb Co.) $(n=5)$. Immediately after chemotherapy administration, $100 \mu \mathrm{g}$ of ${ }^{14} \mathrm{C}$-labeled DAB4 $(18,24)$ were injected intravenously. The specific radioactivity value of ${ }^{14} \mathrm{C}-\mathrm{DAB} 4 \mathrm{mAb}$ was $130 \mathrm{dpm} / \mu \mathrm{g}$. After $48 \mathrm{~h}$, mice were humanely killed by cardiac puncture and whole blood and organs collected, solubilized with Solvable (PerkinElmer) for $2 \mathrm{~h}$ at $50^{\circ} \mathrm{C}$, and decolorized using $30 \% \mathrm{H}_{2} \mathrm{O}_{2}$ (Sigma-Aldrich). UltimaGold scintillation liquid (PerkinElmer) was added, and samples were analyzed using a Packard Tri-Carb $3100 \beta$ counter (PerkinElmer). Radioactivity in organs was normalized to the weight of the organ, and the accumulation of radiolabeled antibody was calculated as the percentage of radioactivity per gram in the organs over the radioactivity of the injected dose at $0 \mathrm{~h}(\% \mathrm{ID} / \mathrm{g})$.

\section{Scintigraphic Imaging of EL4 Tumor-Bearing Mice}

DAB4 $\mathrm{F}(\mathrm{ab})_{2}$ fragments were prepared using agarose-immobilized pepsin according to the manufacturer's instructions (Pierce) and were biotinylated using EZ-Link Biotin-LC-NHS (Pierce) in a 30-fold molar excess to yield an average of 3-5 biotin molecules per antibody molecule. DAB4 F(ab) ${ }_{2}$-LC-biotin $(50 \mu \mathrm{g})$ was administered intravenously to untreated C57BL/6 mice (control) with 4-d-old EL4 tumor implants $(n=3)$ and to mice that had received chemotherapy (etoposide [19 $\mathrm{mg} / \mathrm{kg}$ ] and cyclophosphamide [25 mg/kg]) with 7-d-old EL4 tumor implants $(n=3)$. This protocol allowed for comparison of animals with size-matched tumors, a methodology that mimics clinical practice. Twenty-four hours later, mice were administered intravenous injections of $50 \mu \mathrm{g}(100 \mathrm{MBq} / \mathrm{mg})$ of streptavidin-DOTA radiolabeled with ${ }^{111}$ In (PerkinElmer) as previously described $(18,20)$. Mice were humanely killed via cervical dislocation 2 and $24 \mathrm{~h}$ later. Whole-body static images were acquired for $18 \mathrm{~min}$ using a scintigraphic $\gamma$ camera 
(Starcam 300 M; GE Healthcare). After imaging, organs were dissected and the $\% \mathrm{ID} / \mathrm{g}$ determined.

\section{Biodistribution of DAB4 in Human Carcinoma Models}

PC-3 and Panc-1 carcinomas were established in 6- to 8-wk-old $\mathrm{BALB} / \mathrm{c}$ nude mice by subcutaneous injection of $5 \times 10^{6}$ cells in $50 \%$ Matrigel (Becton-Dickinson) in phosphate-buffered saline into the right flank of the mice (17). Mice bearing $200 \mathrm{~mm}^{3}$ PC-3 tumors were either untreated (control) or treated with etoposide $(50 \mathrm{mg} / \mathrm{kg}$ ) by intraperitoneal injection. Mice bearing $100 \mathrm{~mm}^{3}$ Panc-1 tumors were either untreated (control) or treated with intravenous injection of gemcitabine $(150 \mathrm{mg} / \mathrm{kg}$; Eli Lilly) and cisplatin $(6 \mathrm{mg} / \mathrm{kg})$. Single-cell suspensions of tumor tissue were prepared for flow cytometric analysis of treatment-induced cell death (7-AAD) and DAB4 binding to dead tumor cells $(n=3)$ as previously described (20). Apoptotic cells in tumor sections were detected using a fluorescein in situ cell death detection kit (TUNEL; Roche) following the manufacturer's instructions. ${ }^{111}$ In-DOTA-DAB4 or ${ }^{111}$ In-DOTA-Sal5 (100 $\mu \mathrm{g}$ at a specific activity of $77.7 \mathrm{MBq} / \mathrm{mg}$ ) was given by intravenous injection immediately after chemotherapy. At $72 \mathrm{~h}$ after administration, mice $(n=5)$ were humanely killed by cardiac puncture, and the $\% \mathrm{ID} / \mathrm{g}$ was measured. For tumor imaging, mice $(n=2)$ were administered $14.8 \mathrm{MBq}$ of ${ }^{18} \mathrm{~F}-\mathrm{FDG}$ and imaged $90 \mathrm{~min}$ later at the Peter MacCallum Cancer Centre on a Philips Mosaic small-animal PET scanner as described previously (25). After imaging, mice were intravenously administered $100 \mu \mathrm{g}$ of DAB4-DOTA radiolabeled with ${ }^{177} \mathrm{Lu}$ (Perkin-Elmer), with a specific activity of $90 \mathrm{MBq} / \mathrm{mg}$, and euthanized $48 \mathrm{~h}$ later. Tumors were excised and snap-frozen, and high-resolution digital autoradiography was performed on $20-\mu \mathrm{m}$ frozen tumor sections using a MicroImager (Biospace Lab).

\section{Analysis of DAB4 Binding in Blood Samples from Patients with ALL and SCLC}

A blood sample $(10 \mathrm{~mL})$ was collected from an ALL patient and subjected to ficoll gradient separation. After incubation with red blood cell lysis buffer, the lymphocytes were untreated (control) or treated with etoposide ( $40 \mu \mathrm{g} / \mathrm{mL})$, cisplatin $(20 \mu \mathrm{g} / \mathrm{mL})$, or gemcitabine (200 $\mu \mathrm{g} / \mathrm{mL}$ ) alone or in combination for 24,48 , or $72 \mathrm{~h}$. Cells were washed and incubated in triplicate with $10 \mu \mathrm{g}$ of DAB4 or Sal5 per milliliter, followed by fluorescent secondary antibody and 7-AAD staining as described above, and then analyzed immediately by flow cytometry. The specific binding of DAB4 was analyzed in dead (7-AAD $\left.{ }^{+}\right)$cells, and the net mean fluorescence intensity (MFI) was calculated by subtracting the MFI of each sample after staining with the Sal5 isotype control $\mathrm{mAb}$ from the MFI after staining with DAB4.

Heparinized blood samples from 2 SCLC patients were collected before and after standard chemotherapy (intravenously administered carboplatin at an area under the curve (AUC) of 5 on day 1 and etoposide $100 \mathrm{mg} / \mathrm{m}^{2}$ on days 1, 2, and 3) at the Royal Adelaide Hospital Cancer Centre. Blood samples were also obtained from healthy volunteers. Aliquots of blood $(100 \mu \mathrm{L})$ were blocked using FcR Blocking Reagent (Miltenyi Biotec) and then incubated with 10 $\mu \mathrm{g}$ of DAB4 or Sal5 per milliliter, followed by fluorescent secondary antibody as described in the previous section. After washing, cells were incubated for $10 \mathrm{~min}$ in red blood cell lysis buffer containing 7 -AAD $(2 \mu \mathrm{g} / \mathrm{mL})$ and then analyzed immediately by flow cytometry. The specific binding of DAB4 (net MFI) was analyzed in dead cells (7$\mathrm{AAD}^{+}$) and corrected for any nonspecific staining observed in treated cells incubated with the antibody isotype control (Sal5). Blood from 1 patient was subjected to CELLection Epithelial Enrich (Life Technologies) per the manufacturer's instructions and stained with Sal5/ DAB4 and 7-AAD as described above. At least 10,000 events were acquired per sample.

\section{Statistical Analysis}

Statistical analysis was performed using Prism software (version 4.0; GraphPad). Unless otherwise stated, intergroup comparisons were made by 2 -way ANOVA. Data are shown as mean \pm SEM. Statistical significance was reached when the $P$ value was less than 0.05 .

\section{RESULTS}

\section{Binding of DAB4 to Dead Tumor Cells After Treatment with Different Apoptotic Stimuli In Vitro}

Jurkat cells were treated with various apoptotic stimuli, and the extent of DNA DSB (manifested as $\gamma$-H2AX foci), cell death, and DAB4 binding was examined. Cisplatin or ionizing radiation treatments, which activate the intrinsic apoptotic pathway, resulted in an increase in $\gamma-\mathrm{H} 2 \mathrm{AX}$ formation as early as $5 \mathrm{~h}$ after treatment (Supplemental Fig. 1A; supplemental materials are available at http://jnm.snmjournals.org). At $24 \mathrm{~h}$ of treatment, apoptosis was evident with activation of caspase-3 (Supplemental Fig. 1B), loss of mitochondrial potential (Rho123-positive cells), and detection of externalized phosphatidylserine (Annexin V-positive cells) (Supplemental Fig. 2). In contrast, activation of the extrinsic apoptotic pathway via ligation of the Fas receptor with an anti-CD95 $\mathrm{mAb}$ resulted in activation of caspase- 3 as early as $5 \mathrm{~h}$ after treatment (Supplemental Fig. 1B). $\gamma-\mathrm{H} 2 \mathrm{AX}$ was detected at $5 \mathrm{~h}$ after Fas ligation and may result from activity of the Fas-induced Caspaseactivated DNase complex (26). The time course of DAB4 binding was similar to that for each of $\gamma-\mathrm{H} 2 \mathrm{AX}$ formation and caspase- 3 activation after each apoptotic stimulus, with an increase in DAB4 binding that was rapid and sustained after cisplatin or ionizing radiation, transient after Fas ligation, and absent in serum-starved cells (Fig. 1).
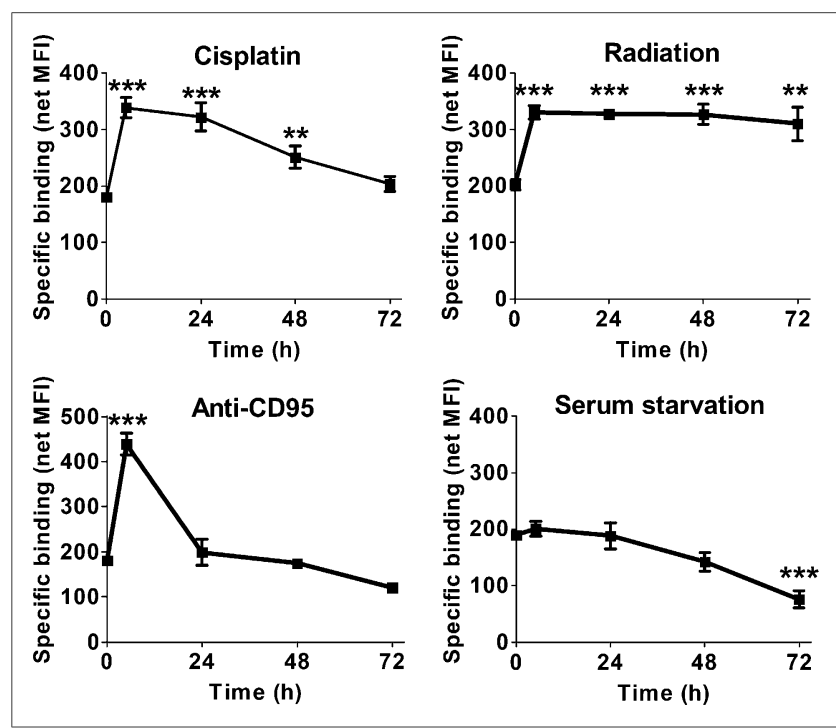

FIGURE 1. Cellular binding of DAB4 to Jurkat cells treated with different apoptotic stimuli. Jurkat cells were treated with cisplatin $(20 \mu \mathrm{g} / \mathrm{mL})$, ionizing radiation (15 Gy), or anti-CD95 mAb $(250 \mathrm{ng} / \mathrm{mL})$ or were deprived of serum in continuing culture. After fixation and permeabilization, DAB4 binding to permeabilized dead cells was examined. Data shown are net MFI of DAB4 after subtraction of signal from isotype control mAb, Sal5. $n=3$. ${ }^{* \star} P<0.01$, ${ }^{\star \star \star} P<0.001$ (1-way ANOVA, Tukey post hoc test). 


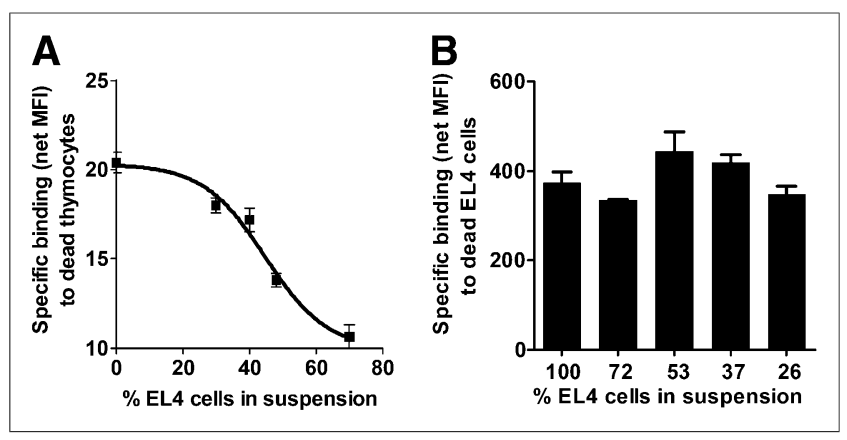

FIGURE 2. DAB4 binds preferentially to dead malignant cells in presence of dead normal cells in vitro. Fixed number of dead CFSE-labeled thymocytes was mixed with increasing number of dead EL4 cells, and DAB4 or antibody isotype control (Sal5) binding to either cell type was analyzed by flow cytometry. (A) MFI of DAB4 binding (after subtraction of Sal5 MFI) to dead thymocytes (gated as $\mathrm{CFSE}^{+}$cells) was plotted as function of percentage of dead EL4 cells in total number of dead cells analyzed. (B) MFI of DAB4 binding to EL4 cells (gated as $\mathrm{CFSE}^{-}$cells) as function of percentage of EL4 cells in total number of dead cells analyzed $(n=3)$. CFSE $=$ carboxyfluorescein succinimidyl ester.

\section{Differential Binding of DAB4 to Dead Tumor and Normal Cells In Vitro}

Mouse thymocytes and EL4 thymic lymphoma cells were treated with cisplatin to induce greater than $90 \%$ cell death. A set number of dead thymocytes was combined with an increasing proportion of dead EL4 cells, and DAB4 binding to the 2 different cell types was examined. DAB4 bound with low avidity when incubated with only dead thymocytes as measured by the MFI of antibody binding (Fig. 2A). As dead EL4 cells were mixed with dead thymocytes, the binding of DAB4 to dead thymocytes reduced further and reached near-undetectable levels when $72 \%$ of the cell population contained dead EL4 cells (Fig. 2A). Conversely, the MFI of DAB4 binding to dead EL4 cells alone was 20-fold higher than the MFI of DAB4 binding to dead thymocytes. When dead thymocytes were added to dead EL4 cells, the high binding avidity of DAB4 for dead EL4 cells was not significantly affected (Fig. 2B).

\section{Uptake of DAB4 In Vivo Is Affected by Clearance of Dead Tumor Cells}

Because DAB4 bound with higher avidity to dead tumor cells than dead normal cells in vitro, we reasoned that a defect in the clearance of dead cells in vivo would reveal an accumulation of dead tumor cells, which could be targeted by DAB4. To examine this, we used $C 1 q$ knock-out $\left(C l q a^{-1-}\right)$ mice, which lack the first component of the complement pathway (C1q) and manifest an accumulation of apoptotic cells in the glomeruli (23). First, the impaired clearance of apoptotic tumor cells associated with Clqa deficiency was examined by administering apoptotic Jurkat cells to wild-type (C57BL/6) or Clqa ${ }^{-1-}$ mice and measuring the level of plasma dsDNA as a marker of dead cell clearance (27). As expected, injection of apoptotic Jurkat cells in C57BL/6 mice increased the amount of dsDNA present in the plasma (Fig. 3A). When apoptotic Jurkat cells were administered to $C 1 q a^{-1-}$ mice, a significantly higher level of plasma dsDNA was detected, compared with similarly treated C57BL/6 mice (Fig. 3A). Next, the biodistribution of ${ }^{14} \mathrm{C}$-DAB4 in C57BL/6 and Clqa ${ }^{-1-}$ EL4 tumor-bearing mice that had either been untreated or treated with chemotherapy was examined. The uptake of DAB4 was selectively and significantly increased within tumors of $\mathrm{C} 57 \mathrm{BL} / 6$ mice after chemotherapy

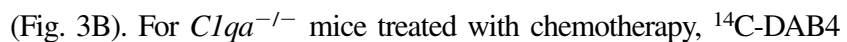
tumor accumulation was significantly higher than that observed in tumors of C57BL/6 mice treated with chemotherapy (Fig. 3B). There were no differences in the uptake of ${ }^{14} \mathrm{C}$-DAB4 in any other tissue from C57BL/6 or Clqa ${ }^{-1-}$ mice after chemotherapy.

\section{Whole-Body Imaging and Biodistribution of Pretargeted} Biotin-DAB4 After Cytotoxic Treatment In Vivo

Next, we aimed to investigate whether pretargeting of biotinylated $\mathrm{F}(\mathrm{ab})_{2}$ fragments of DAB4 enabled their detection $24 \mathrm{~h}$ later in EL4 tumors via the administration of ${ }^{111} \mathrm{In}$-streptavidin to mice given chemotherapy or not. Using whole-body $\gamma$-camera imaging, we detected tumor accumulation of DAB4-F(ab) $)_{2}$ as early as $2 \mathrm{~h}$ after the injection of ${ }^{111}$ In-streptavidin (Supplemental Fig. 3A). Tissue-specific analysis revealed a 3-fold increase in DAB4-F(ab) binding within EL4 tumors from mice given chemotherapy at $2 \mathrm{~h}$ after ${ }^{111} \mathrm{In}$-streptavidin, and a similar increase was observed at 24 $\mathrm{h}$ after radiotracer administration (Supplemental Figs. 3A and 3B).

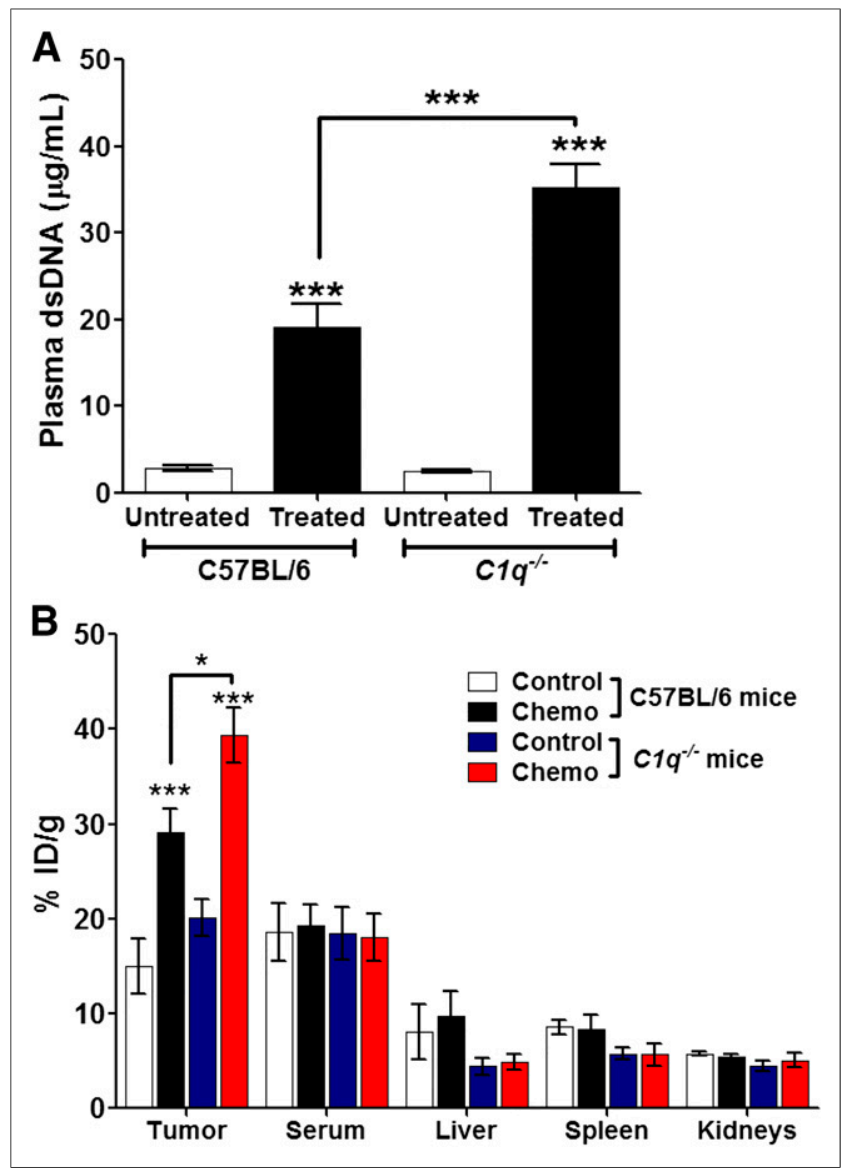

FIGURE 3. Clearance of apoptotic cells in vivo modulates tumor accumulation of DAB4. (A) C57BL/6 mice and syngeneic $\mathrm{C} \mathrm{qa}^{-/-}$mice were untreated or administered apoptotic Jurkat cells intraperitoneally. Plasma was collected $24 \mathrm{~h}$ later, and level of dsDNA present was measured using Quant-iT PicoGreen dsDNA kit $(n=5)$. ${ }^{* \star *} P<0.001$. (B) EL4 tumor-bearing C57BL/6 and $\mathrm{C} \mathrm{qa}^{-/-}$mice were untreated (Control) or treated with cyclophosphamide and etoposide (Chemo). ${ }^{14} \mathrm{C}-\mathrm{DAB} 4(100 \mu \mathrm{g}$ at specific activity of $130 \mathrm{dpm} / \mu \mathrm{g}$ ) was administered $24 \mathrm{~h}$ later, organs were collected $48 \mathrm{~h}$ later, and $\% \mathrm{ID} / \mathrm{g}$ was determined $(n=5)$. ${ }^{*} P<0.05$, compared with chemotherapy-treated C57BL/6 mice. ${ }^{\star \star *} P<0.001$, compared with control mice. 


\section{Biodistribution of DAB4 in Xenograft Models of Human Carcinoma}

We have shown in this study and in others $(17,18,20)$ the specific and chemotherapy-dependent tumor uptake of DAB4 in the syngeneic murine EL4 lymphoma model. However, the biodistribution of DAB4 in human carcinoma xenograft models has not been reported previously. Therefore, we examined the biodistribution of DAB4 in human cancer xenograft models. Treatment of mice bearing the human prostate cancer xenograft PC-3 with

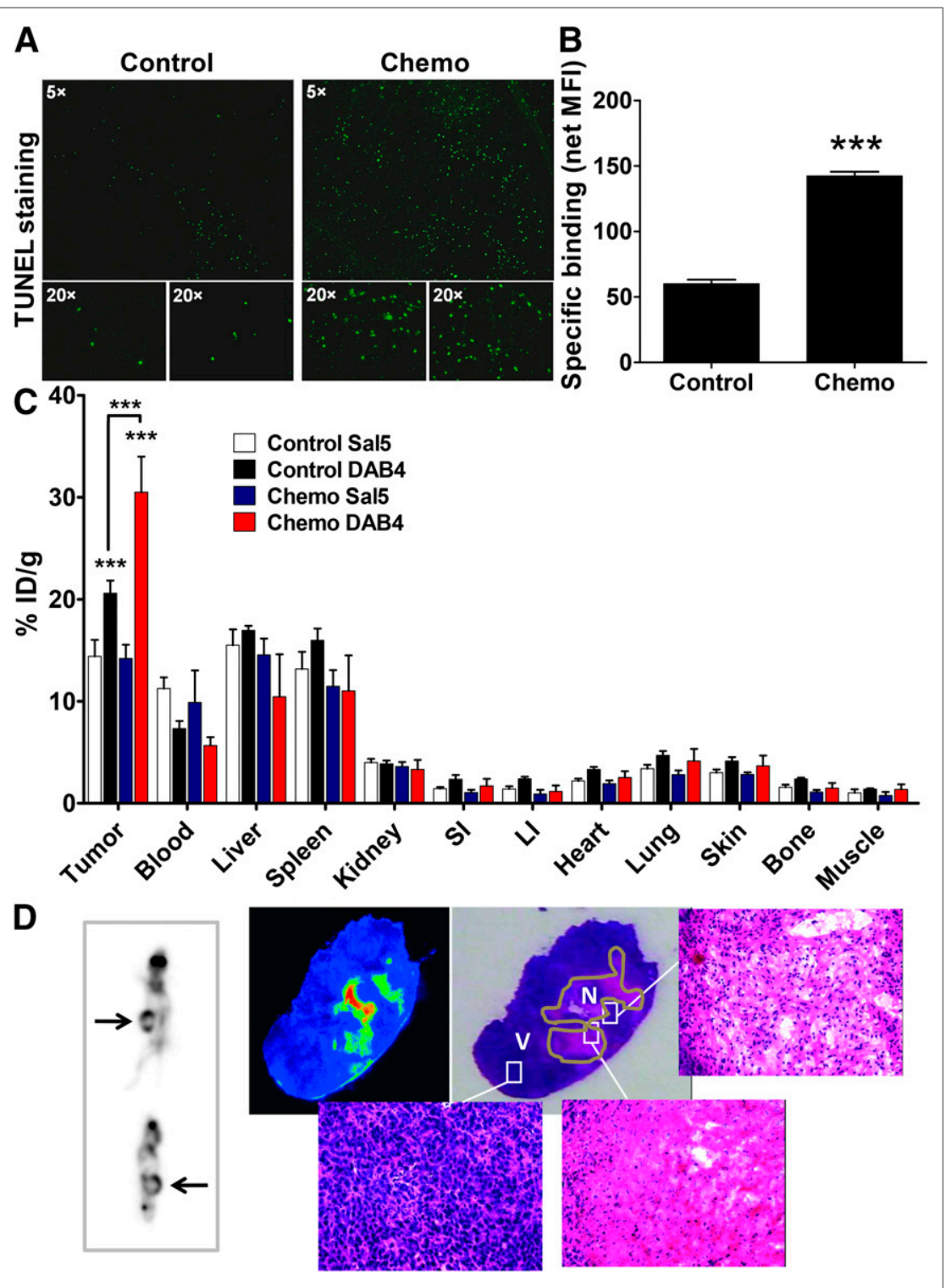

FIGURE 4. Biodistribution of radiolabeled DAB4 in mice bearing human carcinoma xenografts. PC-3 tumor-bearing BALB/c nude mice were untreated (Control) or treated with etoposide (50 $\mathrm{mg} / \mathrm{kg}$ ) (Chemo) intraperitoneally, and tumors were collected $72 \mathrm{~h}$ after treatment for TUNEL staining (A) or flow cytometric analysis (B) of specific binding of DAB4 to dead $\left(7-A A D^{+}\right)$cells, $n=3$. (C) ${ }^{111} \mathrm{In}$-DOTA-DAB4 or ${ }^{111} \mathrm{In}$-DOTA-Sal5 $(100 \mu \mathrm{g}$ at specific activity of $77.7 \mathrm{MBq} / \mathrm{mg})$ was administered after chemotherapy, mice were euthanized $72 \mathrm{~h}$ later, and accumulation of radiolabeled antibody in organs (\%ID/g) was measured $(n=5) .{ }^{* \star \star} P<0.001$. (D, left) Untreated PC-3 tumor-bearing mice were administered $14.8 \mathrm{MBq}$ of ${ }^{18} \mathrm{~F}-\mathrm{FDG}$ and imaged $90 \mathrm{~min}$ later before injection of ${ }^{177} \mathrm{Lu}-\mathrm{DOTA}-\mathrm{DAB} 4$ (top, anterior view; bottom, lateral view; tumor arrowed). (D, right) Tumors were collected $48 \mathrm{~h}$ later for high-resolution $\beta$ autoradiography and hematoxylin and eosin staining $(n=2)$. $\mathrm{LI}=$ large intestine; $\mathrm{N}=$ necrotic; $\mathrm{SI}=$ small intestine; $\mathrm{V}=$ viable.
$50 \mathrm{mg}$ of etoposide per kilogram doubled tumor cell death (7-AAD ${ }^{+}$ cells) from $16 \% \pm 1 \%$ (mean $\pm \mathrm{SEM})$ to $33 \% \pm 1 \%(n=3, P<$ $0.01)$ at $72 \mathrm{~h}$ after chemotherapy. Chemotherapy also increased the number of TUNEL-positive cells within the tumor (Fig. 4A), indicating that more dead tumor cell targets would be present after chemotherapy for DAB4 targeting. Indeed, the increase in chemotherapy-induced cell death was associated with increased DAB4 binding in cell suspensions prepared from excised tumors after chemotherapy (Fig. 4B). Tissue biodistribution analysis revealed that DAB4 binding within the PC-3 tumors was significantly higher in untreated mice than the isotype control antibody (Sal5) and that chemotherapy significantly increased the intratumoral accumulation of DAB4 (Fig. 4C). Chemotherapy did not affect the uptake of DAB4 in other organs, a result that concurs with our previous observations in the syngeneic EL4 murine tumor model. Similar chemotherapy-induced cell death and increased tumor uptake of DAB4 was also observed in the human pancreatic cancer (Panc-1) xenograft model after chemotherapy (Supplemental Fig. 4). Wholebody PET imaging of PC-3 tumor-bearing mice revealed peripheral tumor uptake of ${ }^{18} \mathrm{~F}$-FDG, with minimal ${ }^{18} \mathrm{~F}$-FDG uptake in the tumor center (Fig. 4D), likely representing an area of necrosis. High-resolution autoradiography of excised $\mathrm{PC}-3$ tumors showed binding of ${ }^{177} \mathrm{Lu}$-DOTA-DAB4 within specific regions of the tumor, and histologic examination using hematoxylin and eosin stains identified those areas being of poor tissue morphology and necrosis (Fig. 4D). Similar intratumoral binding patterns of DAB4 in the human squamous carcinoma (A431) xenograft model were also observed (Supplemental Fig. 5).

\section{Binding of DAB4 to Primary Human Cancer Cells Ex Vivo}

Lymphocytes from an ALL patient were treated with DNA-damaging drugs in vitro and then assayed for DAB4 binding. As shown in Figure 5, significant increases in per-cell binding of DAB4 were detected among dead ALL cells that had been killed in vitro with cytotoxic drugs, compared with the untreated control cells. DAB4 binding was the greatest when leukemic cells were treated with a combination of chemotherapeutic drugs, with the increased binding of DAB4 to dead ALL cells peaking between 24 and $48 \mathrm{~h}$ after treatment in most cases. Similarly to our previous results (16), a decrease in DAB4 binding from this peak was observed at $72 \mathrm{~h}$ after exposure and may be related to disintegration of apoptotic bodies.

To further elucidate whether DAB4 binding was specific for treatment-induced dead cancer 


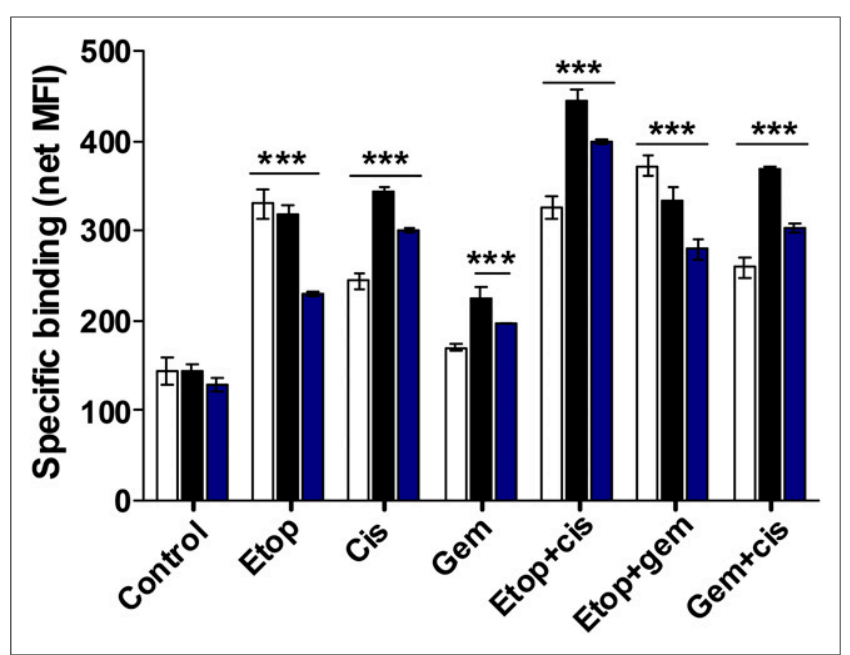

FIGURE 5. Specific binding of DAB4 to human ALL cells after in vitro treatment with DNA-damaging cytotoxic drugs. Leukemic blasts from ALL patient were untreated (Control) or treated with etoposide (Etop; $40 \mu \mathrm{g} / \mathrm{mL}$ ), cisplatin (Cis; $20 \mu \mathrm{g} / \mathrm{mL}$ ), gemcitabine (Gem; $200 \mu \mathrm{g} / \mathrm{mL}$ ), etoposide ( 40 $\mu \mathrm{g} / \mathrm{mL})$ with cisplatin $(20 \mu \mathrm{g} / \mathrm{mL})$ (Etop + cis), etoposide $(40 \mu \mathrm{g} / \mathrm{mL})$ with gemcitabine $(200 \mu \mathrm{g} / \mathrm{mL})($ Etop + gem), or gemcitabine $(200 \mu \mathrm{g} / \mathrm{mL})$ with cisplatin $(20 \mu \mathrm{g} / \mathrm{mL})(\mathrm{Gem}+\mathrm{cis})$. Cells were analyzed by flow cytometry for DAB4 binding after gating based on 7-AAD ${ }^{+}$events. MFI of DAB4 binding was analyzed at $24 \mathrm{~h}$ (white bars), $48 \mathrm{~h}$ (black bars), and $72 \mathrm{~h}$ (blue bars) after treatment $(n=3) .{ }^{* \star \star} P<0.001$.

cells, we analyzed DAB4 binding in blood samples taken from 2 SCLC patients before and after their first cycle of chemotherapy. The per-cell binding of DAB4 to dead cells from SCLC patients before chemotherapy $(0 \mathrm{~h})$ was significantly increased, compared with DAB4 binding seen in samples from healthy volunteers (coded HV1 and HV2; Figs. 6A and 6B). Specific DAB4 binding remained unchanged at $24 \mathrm{~h}$ after chemotherapy and was significantly increased at $48 \mathrm{~h}$ after chemotherapy (Figs. 6A and 6B). This method did not discriminate between the binding of DAB4 to dead normal or cancer cells that may arise in the patient's blood after chemotherapy administration. Therefore, a method was applied to enrich tumor epithelial $\left(\mathrm{EpCAM}^{+}\right)$cells from the blood of a third SCLC patient (Fig. 6C) and a blood sample from a healthy volunteer. Minimal DAB4 binding was observed before chemotherapy whereas, after the first cycle of chemotherapy, a time-dependent increase in DAB4 binding to dead $\mathrm{EpCAM}^{+}$cells was observed, which peaked at $72 \mathrm{~h}$ after chemotherapy (Fig. 6C).

\section{DISCUSSION}

The La antigen is a novel target for the detection of dead tumor cells because it is overexpressed in a variety of cultured human malignant cells $(16,28)$ and in human malignant tissues $(28-30)$. As La becomes accessible after cytotoxic treatment of tumor cells $(16,20)$, examining the prevalence of La provides a new target for exploring tumor responses to treatment. In this study, we demonstrated that DAB4 binds avidly to permeabilized tumor cells after treatment with the apoptotic stimuli of cisplatin, ionizing radiation, or Fas ligation. Furthermore, higher DAB4 binding was associated with an increased abundance of DNA DSBs, which, when unresolved, contribute to cell death. These results are consistent with previously observed increases in DAB4 binding to necrotic tumor cells in vitro (16) and may result from several factors including translocation of La from the nucleus to cytoplasm in association with apoptosis $(31,32)$, changed conformation of the $\mathrm{La}$ protein revealing the DAB4 epitope, or redistribution of $\mathrm{La}$ to DSBs (16). Significantly increased and sustained DAB4 binding to tumor cells was associated only with cytotoxic anticancer treatments because DAB4 binding to serum-starved tumor cells reduced with time of serum starvation. Serum starvation is known to promote autophagy in Jurkat cells (33), and the reduced DAB4 binding may result from catabolism of La antigen-containing structures within autophagic Jurkat cells.

In a competition assay, we showed that DAB4 preferentially bound dead EL4 thymic lymphoma cells, compared with normal counterpart thymocytes. Our previous data show that $\mathrm{La}$ is overexpressed in EL4 cells, compared with thymocytes (18), which may explain the preferential in vitro binding of DAB4 to EL4 cells. Thus, we investigated the link between apoptotic tumor cell clearance in vivo and tumor uptake of DAB4. Tumor-bearing $\mathrm{Clqa}^{-1-}$ mice, which are known to have impaired clearance of apoptotic cells (34), had a significant increase in DAB4 tumor accumulation after chemotherapy, compared with wild-type mice. Despite this apoptotic cell clearance defect, no significant normal tissue accumulation of DAB4 was evident in $\mathrm{Clqa}^{-1-}$ mice even though chemotherapy is likely to increase cell death in normal tissues such as the gut (35).

The mechanisms underlying the differential clearance of apoptotic cells in malignant and normal tissues are not clear. Nonetheless, the prompt clearance of apoptotic cells by professional and nonprofessional phagocytes in normal tissues is well known $(36,37)$. Conversely, in malignant tissues, failure of the rapid clearance of apoptotic cells results in their progression to necrosis with an accompanying loss of cell membrane integrity, allowing antigen-specific binding by DAB4. For example, the release of high mobility group box-1 protein from necrotic tumor cells may contribute to the delay in their clearance (38).

Altogether, these data suggest that the tumor uptake of DAB4 observed here and 
in other tumor models $(17,18,20)$ reflects a general state of impaired intratumoral clearance of apoptotic cells. To show that impaired clearance of postapoptotic necrotic tumor cells increased the availability of DAB4 binding targets, we delivered a biotinylated $\mathrm{F}(\mathrm{ab})_{2}$ fragment of DAB4 $24 \mathrm{~h}$ after chemotherapy but $24 \mathrm{~h}$ before its detection with ${ }^{111}$ In-labeled streptavidin. A $\mathrm{F}(\mathrm{ab})_{2}$ fragment was used to prevent Fc-mediated phagocytosis of bound tumor cells in vivo. In Supplemental Figure 3, $\gamma$-camera images $24 \mathrm{~h}$ after injection of ${ }^{111}$ In-streptavidin together with supporting biodistribution data showed that significant accumulation of DAB4-F $(a b)_{2}$ had been detected in tumors after chemotherapy. Nevertheless, renal uptake of DAB4-F(ab) $)_{2}$ was found to be high, especially at the 24-h time point after chemotherapy. Consequently, DAB4 imaging of tumor response to chemotherapy using a pretargeting technique requires further optimization. The presence of biotin in the kidney confounds detection by labeled streptavidin, and the reverse approach of pretargeting with an antibody-streptavidin conjugate followed by detection with ${ }^{111}$ In-DOTA-biotin would be favored.

Tumor uptake of DAB4 was used to identify tumor cell death in human tumor xenografts. Tissue-specific analyses of mice bearing the human tumor PC-3 and Panc-1 xenografts demonstrated that DAB4 was taken up by tumor tissue and that chemotherapy resulted in a significant increase in intratumoral DAB4 binding. Importantly, chemotherapy did not alter the uptake of DAB4 in healthy tissues, nor were any changes in the tumor accumulation of the isotype control antibody Sal5 observed after chemotherapy in the PC-3 tumor model, confirming selective tumor targeting of DAB4. Furthermore, autoradiography directly demonstrated DAB4 accumulation in necrotic regions of human tumor xenografts, which is similar to another $\mathrm{mAb}$ that identifies necrotic regions of prostate cancer (39).

One of the features of this particular study was to examine the extent of DAB4 binding to primary samples from cancer patients. DAB4 was found to bind with high avidity to cells isolated from the blood of an ALL patient when treated with chemotherapy in vitro. DAB4 also bound to cells isolated from the blood of SCLC patients who had received chemotherapy, while showing minimal binding to the blood from healthy volunteers. Enrichment of circulating tumor cells by EpCAM selection, which is expressed by most tumor cells (40), revealed that DAB4 binding was specific for circulating tumor cells and that chemotherapy further increased DAB4 binding. Although the patient numbers were small, these results indicate the potential application of DAB4 as a diagnostic test component for measuring chemotherapy responses in vivo and warrant further investigation.

\section{CONCLUSION}

The selectivity of DAB4 for dead tumor cells appeared to be related to relative differences in the efficiencies of apoptotic cell clearance between normal and malignant tissues. When given after chemotherapy, DAB4 accumulates where there is an excess of apoptotic cells in tumors (18), but its lack of accumulation in normal tissues is consistent with the known efficiency of physiologic apoptotic cell clearance $(35,36)$. Hence, this work provides further support for using $\mathrm{DAB} 4 \mathrm{mAb}$ as a noninvasive, real-time, in vivo diagnostic marker of tumor cell death resulting from DNA-damaging anticancer treatments.

\section{DISCLOSURE}

The costs of publication of this article were defrayed in part by the payment of page charges. Therefore, and solely to indicate this fact, this article is hereby marked "advertisement" in accordance with 18 USC section 1734. This work was supported in part by NHMRC project grant ID511303 and Oncaidia Ltd. Fares Al-Ejeh and Jocelyn M. Darby were employees of Oncaidia Ltd. Fares AlEjeh, Jocelyn M. Darby, and Michael P. Brown are coinventors on APOMAB patents owned by Medvet Pty Ltd. All authors had control of the data presented in this manuscript. No other potential conflict of interest relevant to this article was reported.

\section{ACKNOWLEDGMENTS}

We thank Dr. Daniel Thomas (Royal Adelaide Hospital) for providing leukemia samples, Kate Pensa (Royal Adelaide Hospital) for her assistance with ${ }^{14} \mathrm{C}$-labeling studies, Laura Kirby (Peter MacCallum Cancer Centre) for her technical assistance with PET imaging and animal work, Dr. Peter Eu (Peter MacCallum Cancer Centre) for ${ }^{177} \mathrm{Lu}$ radiolabeling of antibody, and the staff at the Institute of Medical and Veterinary Sciences Animal Care Facility for their assistance with animal care.

\section{REFERENCES}

1. Eisenhauer EA, Therasse P, Bogaerts J, et al. New response evaluation criteria in solid tumours: revised RECIST guideline (version 1.1). Eur J Cancer. 2009; 45:228-247.

2. Wahl RL, Jacene H, Kasamon Y, Lodge MA. From RECIST to PERCIST: evolving considerations for PET response criteria in solid tumors. $J$ Nucl Med. 2009;50(suppl 1):122S-150S.

3. Alakus H, Batur M, Schmidt M, et al. Variable ${ }^{18} \mathrm{~F}$-fluorodeoxyglucose uptake in gastric cancer is associated with different levels of GLUT-1 expression. Nucl Med Commun. 2010;31:532-538.

4. Shreve PD, Anzai Y, Wahl RL. Pitfalls in oncologic diagnosis with FDG PET imaging: physiologic and benign variants. Radiographics. 1999;19:61-77.

5. Workman P, Aboagye EO, Chung YL, et al. Minimally invasive pharmacokinetic and pharmacodynamic technologies in hypothesis-testing clinical trials of innovative therapies. J Natl Cancer Inst. 2006;98:580-598.

6. Bhosle SM, Huilgol NG, Mishra KP. Apoptotic index as predictive marker for radiosensitivity of cervical carcinoma: evaluation of membrane fluidity, biochemical parameters and apoptosis after the first dose of fractionated radiotherapy to patients. Cancer Detect Prev. 2005;29:369-375.

7. Chang J, Ormerod M, Powles TJ, Allred DC, Ashley SE, Dowsett M. Apoptosis and proliferation as predictors of chemotherapy response in patients with breast carcinoma. Cancer. 2000;89:2145-2152.

8. Fadok VA, Voelker DR, Campbell PA, Cohen JJ, Bratton DL, Henson PM. Exposure of phosphatidylserine on the surface of apoptotic lymphocytes triggers specific recognition and removal by macrophages. J Immunol. 1992;148:2207-2216.

9. Kartachova M, van Zandwijk N, Burgers S, van Tinteren H, Verheij M, Valdes Olmos RA. Prognostic significance of ${ }^{99 \mathrm{~m}} \mathrm{Tc}$ Hynic-rh-annexin V scintigraphy during platinum-based chemotherapy in advanced lung cancer. J Clin Oncol. 2007;25:2534-2539.

10. Belhocine T, Steinmetz N, Hustinx R, et al. Increased uptake of the apoptosisimaging agent ${ }^{99 \mathrm{~m}} \mathrm{Tc}$ recombinant human Annexin $\mathrm{V}$ in human tumors after one course of chemotherapy as a predictor of tumor response and patient prognosis. Clin Cancer Res. 2002;8:2766-2774.

11. Kartachova MS, Verheij M, van Eck BL, Hoefnagel CA, Olmos RA. Radionuclide imaging of apoptosis in malignancies: promise and pitfalls of Tc-hynicrh-annexin V imaging. Clin Med Oncol. 2008;2:319-325.

12. Tait JF, Cerqueira MD, Dewhurst TA, Fujikawa K, Ritchie JL, Stratton JR. Evaluation of annexin V as a platelet-directed thrombus targeting agent. Thromb Res. 1994;75:491-501.

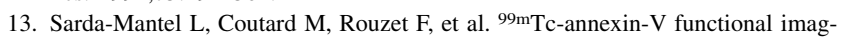
ing of luminal thrombus activity in abdominal aortic aneurysms. Arterioscler Thromb Vasc Biol. 2006;26:2153-2159.

14. Kietselaer BL, Reutelingsperger CP, Heidendal GA, et al. Noninvasive detection of plaque instability with use of radiolabeled annexin A5 in patients with carotidartery atherosclerosis. $N$ Engl J Med. 2004;350:1472-1473.

15. Intine RV, Tenenbaum SA, Sakulich AL, Keene JD, Maraia RJ. Differential phosphorylation and subcellular localization of La RNPs associated with precursor tRNAs and translation-related mRNAs. Mol Cell. 2003;12:1301-1307. 
16. Al-Ejeh F, Darby JM, Brown MP. The La autoantigen is a malignancy-associated cell death target that is induced by DNA-damaging drugs. Clin Cancer Res. 2007;13:5509s-5518s.

17. Al-Ejeh F, Darby JM, Brown MP. Chemotherapy synergizes with radioimmunotherapy targeting la autoantigen in tumors. PLOS ONE. 2009;4:e4630.

18. Al-Ejeh F, Darby JM, Pensa K, Diener KR, Hayball JD, Brown MP. In vivo targeting of dead tumor cells in a murine tumor model using a monoclonal antibody specific for the La autoantigen. Clin Cancer Res. 2007;13:5519s-5527s.

19. Staudacher AH, Al-Ejeh F, Fraser CK, et al. The La antigen is over-expressed in lung cancer and is a selective dead cancer cell target for radioimmunotherapy using the La-specific antibody APOMAB. EJNMMI Res. 2014;4:2.

20. Al-Ejeh F, Darby JM, Tsopelas C, Smyth D, Manavis J, Brown MP. APOMAB, a La-specific monoclonal antibody, detects the apoptotic tumor response to lifeprolonging and DNA-damaging chemotherapy. PLOS ONE. 2009;4:e4558.

21. Kremerskothen J, Nettermann M, op de Bekke A, Bachmann M, Brosius J. Identification of human autoantigen La/SS-B as BC1/BC200 RNA-binding protein. DNA Cell Biol. 1998;17:751-759.

22. Tran HB, Ohlsson M, Beroukas D, et al. Subcellular redistribution of la/SSB autoantigen during physiologic apoptosis in the fetal mouse heart and conduction system: a clue to the pathogenesis of congenital heart block. Arthritis Rheum. 2002;46:202-208.

23. Botto M, Dell'Agnola C, Bygrave AE, et al. Homozygous C1q deficiency causes glomerulonephritis associated with multiple apoptotic bodies. Nat Genet. 1998; 19:56-59.

24. Lu CM, Burton WD, Fitzgerald RL, et al. Mass spectrometric immunoassay for parathyroid hormone-related protein. Anal Chem. 2002;74:5507-5512.

25. Dorow DS, Cullinane C, Conus N, et al. Multi-tracer small animal PET imaging of the tumour response to the novel pan-Erb-B inhibitor CI-1033. Eur J Nucl Med Mol Imaging. 2006;33:441-452.

26. Rogakou EP, Nieves-Neira W, Boon C, Pommier Y, Bonner WM. Initiation of DNA fragmentation during apoptosis induces phosphorylation of $\mathrm{H} 2 \mathrm{AX}$ histone at serine 139. J Biol Chem. 2000;275:9390-9395.

27. Jiang N, Pisetsky DS. The effect of dexamethasone on the generation of plasma DNA from dead and dying cells. Am J Pathol. 2004;164:1751-1759.
28. Sommer G, Dittmann J, Kuehnert J, et al. The RNA-binding protein La contributes to cell proliferation and CCND1 expression. Oncogene. 2011;30:434-444.

29. Trotta R, Vignudelli T, Candini $O$, et al. BCR/ABL activates mdm 2 mRNA translation via the La antigen. Cancer Cell. 2003;3:145-160.

30. Sommer G, Rossa C, Chi AC, Neville BW, Heise T. Implication of RNA-binding protein $\mathrm{La}$ in proliferation, migration and invasion of lymph node-metastasized hypopharyngeal SCC cells. PLOS ONE. 2011;6:e25402.

31. Rutjes SA, Utz PJ, van der Heijden A, Broekhuis C, van Venrooij WJ, Pruijn GJ. The La (SS-B) autoantigen, a key protein in RNA biogenesis, is dephosphorylated and cleaved early during apoptosis. Cell Death Differ. 1999;6:976-986.

32. Ayukawa K, Taniguchi S, Masumoto J, et al. La autoantigen is cleaved in the $\mathrm{COOH}$ terminus and loses the nuclear localization signal during apoptosis. $J$ Biol Chem. 2000;275:34465-34470.

33. von Haefen C, Sifringer M, Menk M, Spies CD. Ethanol enhances susceptibility to apoptotic cell death via down-regulation of autophagy-related proteins. Alcohol Clin Exp Res. 2011;35:1381-1391.

34. Taylor PR, Carugati A, Fadok VA, et al. A hierarchical role for classical pathway complement proteins in the clearance of apoptotic cells in vivo. J Exp Med. 2000;192:359-366.

35. Mason KA, Milas L, Hunter NR, et al. Maximizing therapeutic gain with gemcitabine and fractionated radiation. Int J Radiat Oncol Biol Phys. 1999;44:1125-1135.

36. Wyllie AH, Kerr JF, Currie AR. Cell death: the significance of apoptosis. Int Rev Cytol. 1980;68:251-306.

37. Monks J, Rosner D, Geske FJ, et al. Epithelial cells as phagocytes: apoptotic epithelial cells are engulfed by mammary alveolar epithelial cells and repress inflammatory mediator release. Cell Death Differ. 2005;12:107-114.

38. Friggeri A, Yang Y, Banerjee S, Park YJ, Liu G, Abraham E. HMGB1 inhibits macrophage activity in efferocytosis through binding to the alphavbeta3-integrin. Am J Physiol Cell Physiol. 2010;299:C1267-C1276.

39. Smith-Jones PM, Vallabhajosula S, Navarro V, Bastidas D, Goldsmith SJ, Bander NH. Radiolabeled monoclonal antibodies specific to the extracellular domain of prostate-specific membrane antigen: preclinical studies in nude mice bearing $\mathrm{LNCaP}$ human prostate tumor. J Nucl Med. 2003;44:610-617.

40. Munz M, Baeuerle PA, Gires O. The emerging role of EpCAM in cancer and stem cell signaling. Cancer Res. 2009;69:5627-5629. 